\title{
THE EFFECT OF SOLID LIPID NANOPARTICLES ON TAMOXIFEN-RESISTANT BREAST CANCER
} CELLS

\author{
GAMZE GUNEY ESKILER ${ }^{a *}$, GULSAH CECENER $^{a}$, GOKHAN DIKMEN $^{\mathrm{b}}$, LUTFI GENCc, UNAL EGELIa
}

aDepartment of Medical Biology, Uludag University, Bursa, Turkey, bCenter Research Laboratory, Eskisehir Osmangazi University, Eskisehir, Turkey, cDepartment of Pharmaceutical Technology, Anadolu University, Eskisehir, Turkey

Email: gguneyy@gmail.com

Received: 24 Apr 2016 Revised and Accepted: 29 May 2016

\begin{abstract}
To overcome the acquired Tamoxifen (Tam) resistance in Tam-resistant breast cancer cells without damaging normal cells, we have examined the therapeutic efficacy of Tam-loaded solid lipid nanoparticles (SLNs). Tam-loaded SLNs were produced by hot homogenization method. After characterization, in vitro cytotoxic and apoptotic activity of Tam-SLNs were evaluated in MCF7, MCF7-TamR (Tam-resistant breast cancer cells) and MCF10A cells. Tam-SLNs had an average size nearly $300 \mathrm{~nm}$ and a zeta potential of approximately- $40 \mathrm{mV}$. In vitro cytotoxicity results showed that Tam-SLNs indicated the cytotoxic and apoptotic activity on MCF7 and MCF7-TamR cells. We found that MCF7-TamR cell viability was also suppressed significantly by Tam-SLNs and thus, Tam-SLNs could delay and overcome Tam-resistance ( $<<0.05)$. Furthermore, the Tam-SLNs did not induce apoptosis on MCF10A control cells. The lowest MCF10A cell viability was 83.0\% whereas MCF7 and MCF7-TamR (R↔ and R $\uparrow$ ) cells viability are reduced to $21.98 \%, 27.5 \%$ and $29.4 \%$ at $10 \mu \mathrm{M}$ of Tam-SLNs, respectively ( $<<0.05)$. The obtained results were supported by apoptosis assays. SLNs-delivery system provided therapeutic efficacy to overcome Tam-resistance thanks to unique features of SLNs including small size, drug accumulation in the tumor site and controlled drug release. Therefore, Tam-SLNs may have therapeutic potential for the treatment of TAM-resistant breast cancer.
\end{abstract}

Keywords: Breast cancer, Tamoxifen, Solid lipid nanoparticles, Drug resistance

(C) 2016 The Authors. Published by Innovare Academic Sciences Pvt Ltd. This is an open access article under the CC BY license (http://creativecommons.org/licenses/by/4.0/] DOI: http://dx.doi.org/10.22159/ijpps.2016v8s2.15220.

\section{INTRODUCTION}

Tamoxifen (Tam) has been commonly used in the treatment of estrogen receptor positive $(\mathrm{ER}+)$ breast cancer patients $[1,2]$. Nevertheless, acquired resistance to Tam is one of the most clinical challenges for anti-estrogen therapy though long-term exposure to Tam can cause serious the dose-dependent side effects [3-5]. In order to overcome the acquired drug resistance and improve features of chemotherapeutic drugs for long-term treatment of breast cancers, colloidal drug delivery systems (DDS) have drawn attention in recent years $[6,7]$.

Solid lipid nanoparticles (SLNs), which consist of lipid matrix composition, have potentially wide applications as SLNs deliver the necessary dose of the drug to target issue at the right time by reducing adverse effects on normal cells. Furthermore, SLNs have indicated a high potential for overcoming the multi-drug resistance (MDR) by providing controlled drug release and high capacity for the encapsulation of lipophilic and hydrophilic drugs [8-10].

In the present study, we produced Tam-loaded SLNs by hot homogenization method to investigate the effects of Tam loaded SLNs for overcoming the acquired Tam resistance. After characterization, the cytotoxic and apoptotic effects of Tam-SLNs were identified on the MCF7, MCF7-TamR (Tam-resistant MCF7 breast cancer cell) and MCF10A control cells. Consequently, TamSLNs as a drug delivery system could be potential to overcome the acquired Tam resistance.

\section{MATERIALS AND METHODS}

\section{The preparation and characterization of Tam-SLNs}

Tam-loaded SLNs can be prepared using the hot homogenization technique $[11,12]$. After the stearic acid $(2.5 \%)$ was melted at $80^{\circ} \mathrm{C}$, Tam $(5.0 \%)$ and tween $80(2.5 \%)$ were slowly added into the melted lipid and mixture by the Ultra Turrax homogenizer (Ultra Turrax, Ika) at $20.500 \mathrm{rpm}$ for $10 \mathrm{~min}$. The primary parameters including particle size, polydispersity index and zeta potential of Tam-SLNs were measured using Zetasizer Instrument (Malvern Instrument, UK) at $90^{\circ} \mathrm{C}$ to characterize SLNs.

\section{Cell culture}

MCF7 and MCF7-TamR cells were cultured in DMEM (Sigma, St. Louis, MO) containing 5\% FBS (Sigma, St. Louis, MO) and $100 \mathrm{U} / \mathrm{ml}$ penicillin, and $100 \mathrm{lg} / \mathrm{ml}$ streptomycin (Sigma, St. Louis, MO) whereas MCF10A mammary epithelial control cells were cultured in DMEM/F12 medium supplemented with EGF, hydrocortisone, choleratoxin, insulin, 10\% FBS, penicillin and streptomycin in a 5\% $\mathrm{CO}_{2}$ humified atmosphere at $37{ }^{\circ} \mathrm{C}$. MCF7-TAMR-cells were established by 4-OH Tam (Sigma, St. Louis, MO) exposure and called as $\mathrm{R} \leftrightarrow$ cells, which was treated with continuously $1 \mu \mathrm{M}$ of 4-OH Tam during three months and $\mathrm{R} \uparrow$ cells, which was firstly treated with the minimum concentration $(0.1 \mu \mathrm{M})$ of $4-\mathrm{OH}$ and the concentration was gradually increased to $1 \mu \mathrm{M}$ of $4-\mathrm{OH}$ Tam.

\section{In vitro cytotoxic assay}

To investigate the cytotoxic activity of the Tam-SLNs on MCF7, MCF7-TamR and MCF10A cells, we used the WST-1 assay (Biovision, California) according to the manufacturer's instruction. Firstly, these cells were seeded in 96-well plates at a density of $2 \times 10^{4}$ cells/well and treated with $0.1-10 \mu \mathrm{M}$ of $4-\mathrm{OH}$ Tam. After 24,48 and $72 \mathrm{~h}$ treatment, $10 \mu \mathrm{l}$ of the WST- 1 reagent was added to each well and incubated $30 \mathrm{~min}$ at $37{ }^{\circ} \mathrm{C}$. After incubation, the absorbance was measured at 450-620 nm using Elisa Reader (Sunrise TM, Switzerland).

\section{Apoptosis analysis}

The apoptotic effects of Tam-SLNs on MCF7, MCF7-TamR and MCF10A cells were determined by Annexin-V and dead cell reagent (EMD Millipore) and cell cycle kit (EMD Millipore). The cells were seeded into 6 well plates and then treated with $0.1,1$ and $10 \mu \mathrm{M}$ of Tam-SLNs during $72 \mathrm{~h}$. After incubation, the apoptotic effects of Tam-SLNs was carried out according to manufacturer's protocol and analyzed by Muse Cell Analyser (MuseTM EMD Millipore Co., Hayward, CA, USA). Additionally, the morphological changes of these cells were showed by acridine orange/etidium bromide ( $\mathrm{AO} / \mathrm{EtBr})$ (Sigma, St. Louis, MO) staining. Images were taken with Nikon Eclipse E600 (Nikon, Netherlands). 


\section{Statistical analysis}

The results were statistically evaluated by one-way analysis of variance (ANOVA) for multiple comparisons. $p$ value of less than $0.05(p<0.05)$ was considered as statistically significant.

\section{RESULTS}

\section{Physical characterizations of SLNs}

Particle size and zeta potential of SLNs were determined using Nano brook 90 Plus analyzer. The particle size was ranging from 289 to $302 \mathrm{~nm}$ as well as the zeta potential varied between38 and $-45 \mathrm{mV}$. The small particle size provided a significant advantage for in vitro experiments. However, this negative surface charge indicated the excess of Tam ionized at the interface of SLN. Thus, the lipid ratio should be increased to load into more Tam into SLNs.

\section{In vitro drug sensitivity analysis}

The results from WST-1 assay showed that the cytotoxic activity of Tam-SLNs on MCF7 and MCF7-TamR cells increased with concentration and time-dependent manner (fig. 1A,C,D). On the other hand, Tam-SLNs was slightly affected $(17 \%)$ on MCF10A control cell growth at $10 \mu \mathrm{M}$ of Tam-SLNs for $72 \mathrm{~h}$ exposure due to reducing side effects of Tam (fig. 1B).
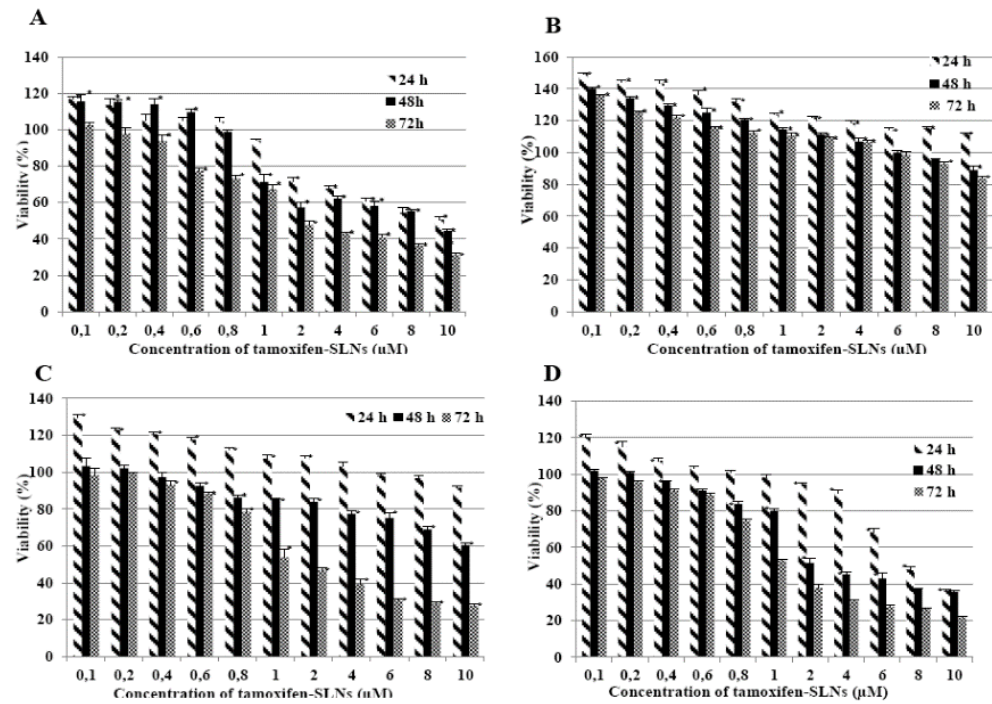

Fig. 1: (A) MCF7, (B) MCF10A, (C) R↔ and (D) R $\uparrow$ cells were exposed to Tam-SLNs at the indicated doses (0.1-10 $\mu \mathrm{M})$ for 24, 48 and $72 \mathrm{~h}$ the apoptotic effects of Tam-SLNs

A

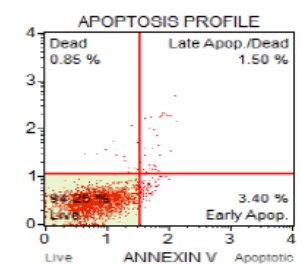

B
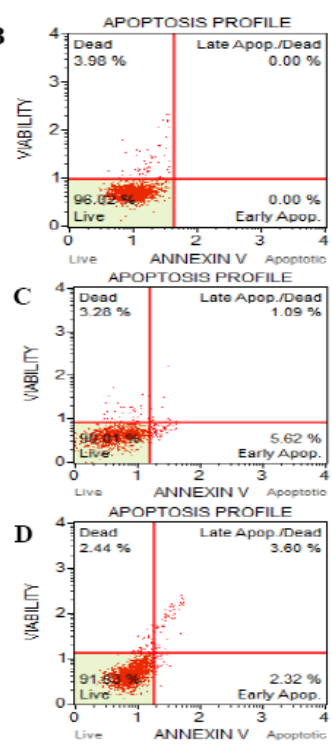

Control
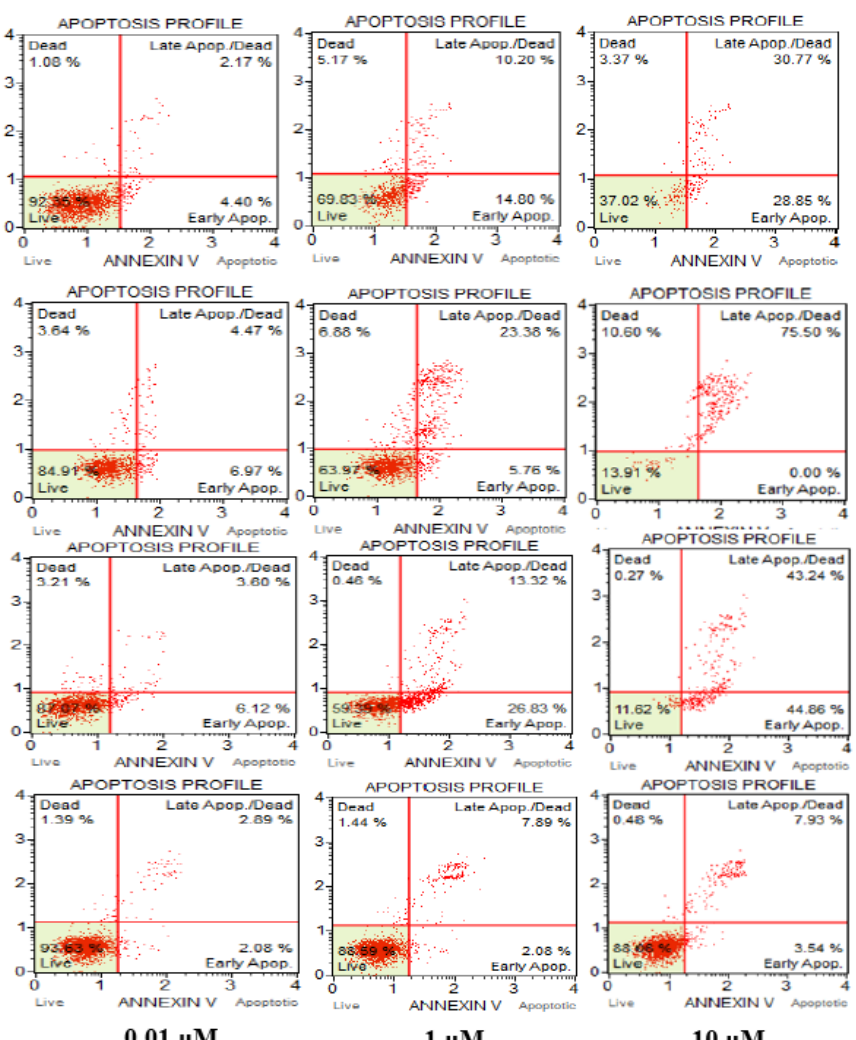

$1 \mu \mathrm{M}$

$10 \mu \mathrm{M}$

Fig. 2: Dose-dependent effects of Tam-SLNs on apoptosis in (A) MCF7, (B) R↔, (C) R $\uparrow$ cell without damaging (D) MCF10A control cells 
The MCF7 cell viability was reduced $98.85 \%$ and $26.65 \%$ at 0.1 and $1 \mu \mathrm{M}$ concentration of Tam-SLNs at $72 \mathrm{~h}(\mathrm{p}<0.05)$, respectively. However, the maximum cytotoxic effects of Tam-SLN was $79.02 \%$ at $10 \mu \mathrm{M}$ concentration $(\mathrm{p}<0.05)$ (fig. $1 \mathrm{~A})$.

In our previous study, we reported that $\mathrm{R} \leftrightarrow$ and $\mathrm{R} \uparrow$ cells were 5.8 and 4 fold resistance to Tam compared to MCF7 cells, respectively. The R $\leftrightarrow$ and $\mathrm{R} \uparrow$ cell viability was decreased $53.6 \%$ and $52.1 \%$ at $1 \mu \mathrm{M}$ concentration whereas, the cells viability was significantly reduced to $27.5 \%$ and $29.4 \%$ (fig. 1C, D). Consequently, TAM indicated cytotoxic effect, even when loaded into the SLNs on MCF7 and MCF7-TamR cells and thus, SLNs formulation could overcome the acquired Tam-resistance.
In the current study, we found that Tam-SLNs induced apoptotic cell death on MCF7 and MCF7-TamR cells after $72 \mathrm{~h}$ treatment (fig. 2). However, Tam-SLNs did not trigger cell death on MCF10A cells (fig. 2D). The percentage of apoptotic cells was $25 \%$ at $1 \mu \mathrm{M}$ concentration on MCF7 cells (fig. 2A), while the apoptotic cell death percentage of $\mathrm{R} \leftrightarrow$ and $\mathrm{R} \uparrow$ were $29.14 \%$ and $40.15 \%$, respectively (fig. 2B,C) compared with control cells. Furthermore, a total apoptotic cell death (early and late apoptosis) of MCF7 cells was $59.66 \%$ at $10 \mu \mathrm{M}$, whereas this rate was $75.50 \%$ and $88.1 \%$ on $\mathrm{R} \leftrightarrow$ and $\mathrm{R} \uparrow$ cells, respectively for $72 \mathrm{~h}$. As a result, Tam-SLNs showed apoptotic effect on MCF7 and MCF7-TamR cells without damaging MCF10A control cells.
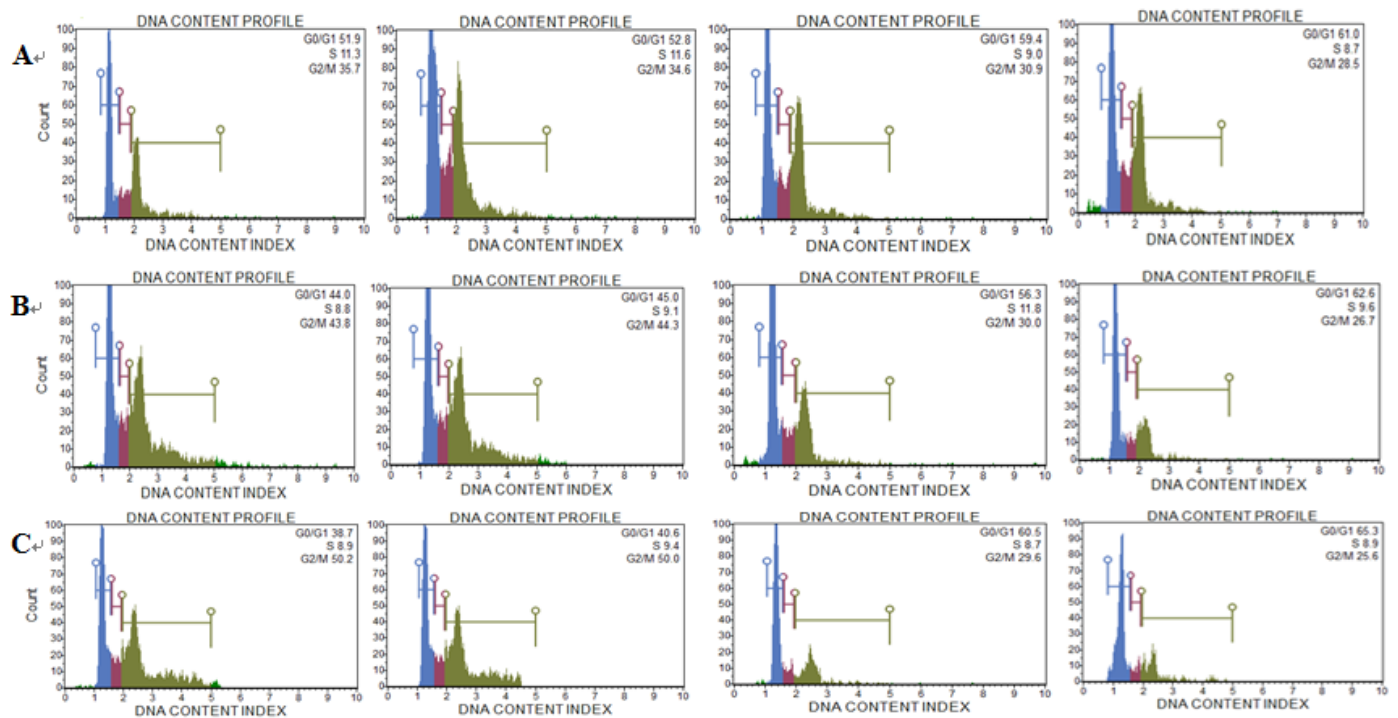

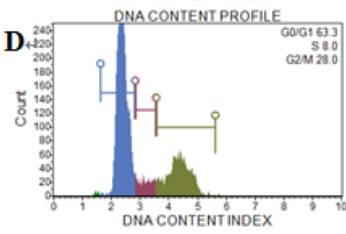

Control

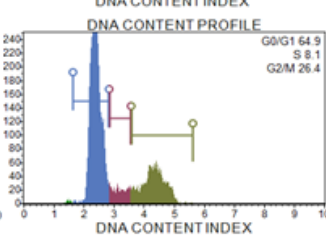

$0.01 \cdot \mu \mathrm{M}$

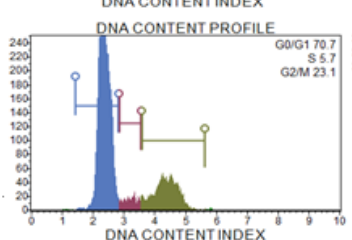

$1 \cdot \mu \mathrm{M}$

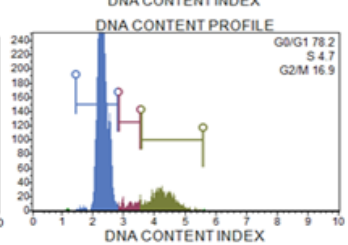

$10 \cdot \mu \mathrm{M}$

Fig. 3: Dose-dependent analysis of cell cycle phases for $72 \mathrm{~h}$. (A) MCF7, (B) $R \leftrightarrow$, (C) R $\uparrow$ and (D) MCF10A cells.

In the present study, cell cycle analysis revealed that $\mathrm{G}_{0} / \mathrm{G}_{1}$ phase of MCF7 and MCF7-TamR cells increased, while a slight increase in $\mathrm{G}_{0} / \mathrm{G}_{1}$ phase of MCF10A cells was observed at $72 \mathrm{~h}$ when treated with Tam-SLNs (fig. 3). The percentage of $\mathrm{G}_{0} / \mathrm{G}_{1}$ phase in MCF7 cells was increased from $51.9 \%$ to $61.0 \%$ whereas the percentage of $\mathrm{G}_{0} / \mathrm{G}_{1}$ phase in $\mathrm{R} \leftrightarrow$ and $\mathrm{R} \uparrow$ cells was significantly elevated to $62.6 \%$ and $65.3 \%$, respectively (fig. $3 \mathrm{~A}-\mathrm{C}$ ). The effects of Tam-SLNs on MCF7-TamR cells led to a much higher proportion of cells accumulation in $\mathrm{G}_{0} / \mathrm{G}_{1}$ phase than MCF7 cells. In conclusion, the percentage of the $G_{0} / G_{1}$ arrest and apoptotic cells of MCF7, MCF7-TaMR and MCF10A cells correlated with the cell proliferation result.

Morphological changes of human breast cancer cells
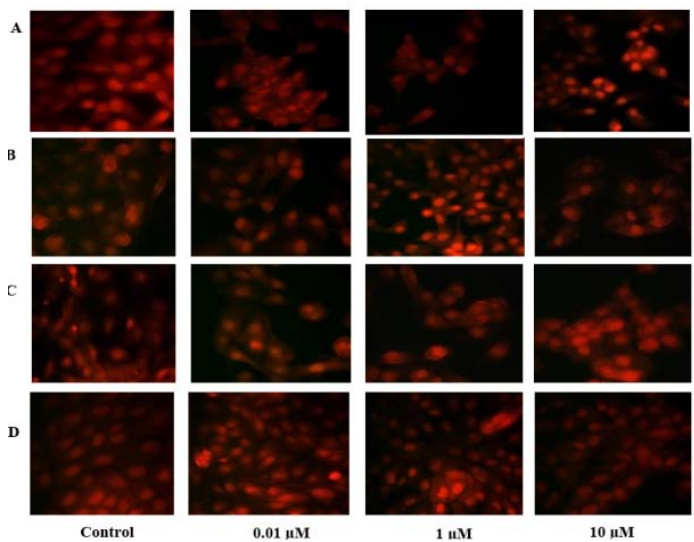

$1 \mathrm{uM}$

Fig. 4: The morphological changes of (A) MCF7, (B) $R \leftrightarrow$, (C) $R \uparrow$ and (D) MCF10A cells were exposed to Tam-SLNs at the indicated doses for $72 \mathrm{~h}$

AO/EtBr staining was choosen for detecting changes in MCF7, MCF7TamR and MCF10A cells morphology. As shown in fig. 4, Tam-SLNs induced apoptosis on MCF7 and MCF7-TamR cells without damaging MCF10A cells. The shape of MCF7 and MCF7-TamR cells were more rounded in concentration-dependent (fig. 4A-C). Additionally, we observed most notably the loss of epithelial-like features, chromatin condensation and holes in these cells. However, the MCF10A cells morphology was nearly similar that of control cells (fig. 4D).

\section{DISCUSSION}

The acquired Tam resistance is a major obstacle in the treatment of ER+breast cancer patients and thus a better understanding of the molecular mechanisms underlying the acquired resistance to Tam is a considerable clinical significance to improve therapeutic strategies for overcoming Tam resistance $[13,14]$.

Drug delivery systems have a great attention as a strategy because of providing accumulation drug inside of the tumor, increasing the therapeutic efficacy of treatment by reducing side effects and overcoming drug resistance mechanisms. SLNs have been developed to enhance the features of current chemotherapeutic drugs by eliminating their drawbacks $[7,15]$. 
In the literature, different nanoparticle formulations (chitosan, liposome, polymeric nanoparticles, etc.) were developed for Tam [16-18]. SLN is especially a good carrier for Tam due to providing its anti-tumoral activity, increasing the solubility of the drug and facilitating the entrapment of high amounts of the drug in the nanoparticles [19]. However, extensive research which determines the role of SLNs on the acquired Tam resistance has not previously been reported, to our knowledge [20,21]. Our findings show that not only Tam-SLNs enhance the anti-tumor effects of Tam but also overcome the acquired Tam-resistance by inducing apoptosis in MCF7 and MCF7-Tam R cells compared with control cells. In conclusion, the TAM-loaded SLNs are promising carriers for breast cancer therapy due to overcoming Tam-resistance and reducing the side effects of Tam.

\section{CONCLUSION}

Nanoparticle-based drug delivery systems for cancer treatment have significant potential for overcoming drug resistance and development of tumor-targeting systems. Our findings suggest that Tam loaded SLNs are a promising and effective strategy for treatment of Tam-resistant breast cancer cells with optimal drug encapsulation efficiency and minimal toxicity towards healthy cells. However, additional studies including in vivo experiments are necessary to evaluate the preclinical efficacy and safety of Tam-SLNs before clinical evaluations in breast cancer patients.

\section{ACKNOWLEDGEMENT}

This study was supported by a grant from the Scientific Research Projects Foundation (BAP) of the Uludag University of Turkey [Project No: OUAP (T)-2014/30].

\section{ABBREVIATION}

Estrogene receptor-positive (ER+), Tamoxifen (Tam), 4-hydroxytamoxifen (4-OH-Tam), MCF7-TamR (MCF7 Tam resistance), Solid lipid nanoparticles (SLNs), Acridine orange (AO), Dulbecco's modified eagle's medium (DMEM), Dulbecco's modified Eagle's medium/nutrient mixture F12 (DMEM-F12), Fetal bovine serum (FBS).

\section{CONFLICTS OF INTERESTS}

The authors declare that they have no conflicts of interest.

\section{REFERENCES}

1. Gradishar WJ. Tamoxifen-what next? Oncologist 2004;9:378-84.

2. Kassam F, Enright K, Dent R, Dranitsaris G, Myers J, Flynn C, et al. Survival outcomes for patients with metastatic triplenegative breast cancer: implications for clinical practice and trial design. Clin Breast Cancer 2009;9:29-33.

3. García-Becerra R, Santos N, Díaz L, Camacho J. Mechanisms of resistance to endocrine therapy in breast cancer: focus on signaling pathways, miRNAs and genetically based resistance. Int J Mol Sci 2012;14:108-45.

4. Nass N, Kalinski T. Tamoxifen resistance: from cell culture experiments towards novel biomarkers. Pathol Res Pract 2015;211:189-97.

5. Viedma-Rodrïguez R, Baiza-Gutman L, SalamancaGom ez F, Diaz-Zaragoza M, M artïnez-Hernandez G, Ruiz
Esparza-Garrido R, et al. M echan ism $s$ associated $w$ ith resistance to tamoxifen in estrogen receptor-positive breast cancer (Review). Oncol Rep 2014;32:3-15.

6. Sutradhar KB, Amin ML. Nanotechnology in cancer drug delivery and selective targeting. ISRN Nanotechnol 2014. Doi.org/10.1155/2014/939378. [Article in Press]

7. Markman JL, Rekechenetskiy A, Holler E, Ljubimova JY Nanomedicine therapeutic approaches to overcome cancer drug resistance. Adv Drug Delivery Rev 2013;65:1866-79.

8. Lasoń E, Ogonowski J. Solid lipid nanoparticles-characteristics, application and obtaining. Chem Int 2011;65:960-7.

9. Muller RH, Keck CM. Challenges and solutions for the delivery of biotech drugs-A review of drug nanocrystal technology and lipid nanoparticles. J Biotechnol 2004;113:151-70.

10. Bhaskar K, Anbu J, Ravichandiran V, Venkateswarlu V, Rao YM. Lipid nanoparticles for transdermal delivery of flurbiprofen: formulation, in vitro, ex vivo and in vivo studies. Lipids Health Dis 2009;8:6.

11. Güney G, Kutlu HM, Genç L. Preparation and characterization of ascorbic acid loaded solid lipid nanoparticles and investigation of their apoptotic effects. Colloids Surf B 2014;121:270-80.

12. Dikmen G, Guney G, Genc L. Characterization of solid lipid nanoparticles containing caffeic acid and determination of its effects on MCF-7 cells. Recent Pat Anticancer Drug Discovery 2015;10:224-32.

13. Clarke R, Tyson JJ, Dixon JM. Endocrine resistance in breast cancer-an overview and update. Mol Cell Endocrinol 2015;418:220-34.

14. Groenendijk FH, Bernards R. Drug resistance to targeted therapies: Déjà vu all over again. Mol Oncol 2014;8:1-17.

15. Hu CMJ, Zhang L. Nanoparticle-based combination therapy toward overcoming drug resistance in cancer. Biochem Pharmacol 2012;83:1104-11.

16. Ravikumara NR, Madhusudhan B. Chitosan nanoparticles for tamoxifen delivery and cytotoxicity to MCF-7 and Vero cells. Pure Appl Chem 2011;83:2027-40.

17. Sant T, Moreira A, Antônio M, Oliveira M De, Nele M, Pinto JC. Effect of tamoxifen in RAFT mini-emulsion polymerization during the synthesis of polymer nanoparticles. Technical Sci Session 2014;24:25-30.

18. Lin YL, Chen $\mathrm{CH}, \mathrm{Wu} \mathrm{HY}$, Tsai NM, Jian TY, Chang YC, et al. Inhibition of breast cancer with transdermal tamoxifenencapsulated lipoplex. J Nanobiotechnol Biomed Central 2016;14:11.

19. Abbasalipourkabir R, Salehzadeh A, Abdullah R. Cytotoxicity of tamoxifen-loaded solid lipid nanoparticles. Delivery Nanoparticle 2009;59-70.

20. Ostad SN, Dehnad S, Nazari ZE, Fini ST, Mokhtari N, Shakibaie $\mathrm{M}$, et al. Cytotoxic activities of silver nanoparticles and silver ions in parent and tamoxifen-resistant T47d human breast cancer cells and their combination effects with tamoxifen against resistant cells. Avicenna J Med Biotechnol 2010; 2:187-96.

21. Devalapally H, Duan Z, Seiden MV, Amiji MM. Modulation of drug resistance in ovarian adenocarcinoma by enhancing intracellular ceramide using tamoxifen-loaded biodegradable polymeric nanoparticles. Clin Cancer Res 2008;14:3193-203. 